\title{
Phonotactics of noun class disambiguation in Xhosa*
}

\author{
Aaron Braver, ${ }^{1}$ Wm. G. Bennett ${ }^{2}$ \\ ${ }^{I}$ Texas Tech University and ${ }^{2}$ Rhodes University
}

\section{Introduction}

Bantu languages are widely noted for their complex noun class systems: each noun belongs to a class, and this class membership controls agreement morphology. Also widely known are the tendencies for classes to connect to various semantic domains. For example, humans are prototypically in classes 1 and 2; plants often in classes 3 and 4; languages and various tools in classes 7 and 8; long, thin things in class 11; abstractions in class 14 , and so forth. ${ }^{1}$ Such categorizations are mere tendencies, though, and the class of a noun root cannot be determined from its meaning, nor is the semantic domain of a noun's meaning predictable from its class. As such, it is standardly assumed that information about noun class membership must be lexically stored. This raises a question: how do speakers manage such complex systems with so many distinct categories? The observation that different classes align with various semantic criteria suggests a deeper internal structure beyond mere arbitrary memorization. In other domains, based on evidence from languages outside of Bantu, it is noted that phonotactics can provide clues about abstract morphology (Tucker et al. 1977, Corbett 1991, Moreton \& Amano 1999, etc.).

In this paper, we argue that Bantu noun class systems may be organized not just on semantic grounds, but also phonological ones. We show that speakers of Xhosa (a Bantu language from South Africa) are influenced by phonotactic patterns when assigning nonce words to noun classes. Since these nonce words are not lexically stored, and were presented with no semantic content, we conclude that phonological factors are the primary basis for speakers to decide their noun class. Our findings suggest that abstract noun class features are not as arbitrary as they would seem on the face of it: rather, the phonological forms of the roots themselves may provide overt and accessible surface clues to this abstract information. More generally, this suggests that arbitrary morphological information may not be as arbitrary as is commonly assumed.

\section{About the noun class system of isiXhosa}

2.1 Background Xhosa (called isiXhosa [isíllbósà] in the language) is a Bantu language in the Nguni family, spoken primarily in south-eastern South Africa, with smaller communities of speakers in Zimbabwe (Kunjo forthcoming), and major urban centers throughout the region.

Xhosa nouns normally consist of a stem and a prefix. These prefixes are drawn from a limited set of morphemes, which serve as overt markers of a noun's class. Xhosa has 15 noun classes, shown in the table in (1). We follow the Bantuist convention of referring to them by numbers, assigned by convention based on the classes reconstructed in Proto-Bantu. Some sources admit a further class, class 17, historically used with locatives. This class is, in all cases, homophonous with class 15 , however, and it is not clear that any real distinction is made synchronically. Most of the classes are organized into singular/plural pairs, with

\footnotetext{
* This work was assisted by much hard work by Danica Kreusch, and we thank her for her collaboration, particularly concerning data collection and experiment design. We also thank Kelly Goldstuck, Olona Tywabi, Msindisi Sam, and Nomvula Sitole for assistance with collecting and understanding data. For insightful discussion and valuable comments, we thank Mark de Vos, Eva-Marie Bloom-Ström, Sharon Rose, Axel Fleisch, Stephan Schulz, Jochen Zeller, Bonny Sands, Richard Bailey, and audiences at Rhodes University, at the 8th World Congress of African Linguistics, and at the 2015 AMP meeting.

${ }^{1}$ For overviews that connect to relevant sources, see Katamba (2003), Idiata (2005), and many others.

2 The first tone is not marked here because it varies predictably between dialect groups. We follow the convention of The Greater Dictionary of IsiXhosa (Tshabe et al. 1989/2003/2006) in leaving such tones unmarked here and throughout. (C) 2016 Aaron Braver and William G. Bennett

Proceedings of AMP 2015

Completed April 11, 2016
} 
odd numbers being classes of singular nouns, with their plurals typically being in class $n+1$. Thus, class 1 nouns have plurals in class 2 , class 5 nouns have plurals in class 6 , etc. Class 11 makes its plurals in class 10, however; members of classes 14 and 15 typically do not have plural forms. Classes 1a and 2a are distinct only in the prefixes on the nouns; they trigger the same agreement marking as classes 1 and 2 , respectively.

(1) Noun class system of Xhosa

\begin{tabular}{|c|c|c|c|c|c|c|}
\hline \multicolumn{2}{|c|}{ Classes (in sg/pl pairs) } & \multicolumn{2}{|l|}{ Singular } & \multicolumn{2}{|l|}{ Plural } & \multirow{2}{*}{$\begin{array}{l}\text { Gloss } \\
\operatorname{person}(s)\end{array}$} \\
\hline $1 / 2$ & um-/aba- & um-ntu & [umnt'u] & aba-ntu & [abant'u] & \\
\hline $1 \mathrm{a} / 2 \mathrm{a}$ & u-/oo- & u-mama & [umama] & oo-mama & [o:mama] & $\operatorname{mama}(\mathrm{s})$ \\
\hline $3 / 4$ & um-/imi- & um-lambo & [umlambo] & imi-lambo & [imilambo] & river(s) \\
\hline $5 / 6$ & i(li)-/ama- & i-gama & [igama] & ama-gama & [amagama] & name(s) \\
\hline $7 / 8$ & isi-/izi- & isi-tya & [isica] & izi-tya & [izica] & $\operatorname{dish}(e s)$ \\
\hline $9 / 10$ & $\mathrm{i}(\mathrm{N})-/ \mathrm{i}(\mathrm{z}) \mathrm{i}(\mathrm{N})-$ & i-nkomo & [ink’omo] & ii-nkomo & [i:yk'omo] & $\operatorname{cow}(\mathrm{s})$ \\
\hline $11 / 10$ & $\mathrm{u}(\mathrm{lu})-/ \mathrm{i}(\mathrm{z}) \mathrm{i}(\mathrm{N})-$ & ulu-su & [ulusu] & izin-tsu & [izints'u] & $\operatorname{stomach}(s)$ \\
\hline 14 & ubu- & ubu-ntu & [ubunt'u] & (no plural) & & humanity \\
\hline 15 & uku- & uku-tya & [ukuca] & (no plural) & & food \\
\hline
\end{tabular}

2.2 The role of phonotactics A number of class markers are potentially homophonous; as such, it is not always possible to predict which class a noun belongs to from its prefix alone. This situation arises most notably for classes 5 and 9. With short, monosyllabic, roots, these classes have distinct exponents: class 5 is [ili-], while class 9 is [i-]. ${ }^{3}$ However, with nouns that are two syllables or longer (which are most nouns of the language), the class 5 prefix has the allomorph [i-]. As such, nouns of the shape i-CVCV could be either class 5, or class 9: the class marker fails to distinguish them overtly. This is not to say that they collapse into the same class: they are discernibly distinct because they form plurals in canonically different ways, and also trigger distinct agreement morphology. But, the class information is not fully determinable from the noun (prefix + stem) itself, despite the presence of an overt class-marking morpheme.

\begin{tabular}{|c|c|c|c|}
\hline & Normal roots $(-\mathrm{CVCV}+)$ & Short roots $(-\mathrm{CV}$ & \\
\hline Class 5: $\{\mathrm{i}-, \mathrm{ili}-\}$ & $\begin{array}{lll}\text { i-khaya [íkhâjà] } & \text { 'home' } \\
\text { i-gama [îgâmà] } & \text { 'name, word' }\end{array}$ & $\begin{array}{ll}\text { ili-wa } & \text { [ílíwá] } \\
\text { ili-tye } & \text { [ilícè] }\end{array}$ & $\begin{array}{l}\text { 'cliff' } \\
\text { 'stone' }\end{array}$ \\
\hline Class 9: $\{\mathrm{i}-\}$ & $\begin{array}{l}\text { i-nkomo [ínk'òmó] 'cow' } \\
\text { i-moto [ímòtó] 'car' }\end{array}$ & $\begin{array}{ll}\text { i-nja } & \text { [índzà }] \\
\text { i-nto } & \text { [ínt'ó }]\end{array}$ & $\begin{array}{l}\text { 'dog', } \\
\text { 'thing' }\end{array}$ \\
\hline
\end{tabular}

2.3 Historical development The homophony of class 5 and class 9 is an innovation of Xhosa; the two classes were historically distinct in Proto-Bantu. Doke (1954) analyzes class 5 as *1i-, and class 9 as *ni-, with both having the same CV shape, but having different consonants. The *1 of class 5 is transparently retained in the [ili-] allomorph that appears with short roots. The ${ }^{*} n$ of class 9 is the presumed source of the nasal in words like [índzà] 'dog', and many class 9 nouns still retain a nasal in this stem-initial position. However, there are also nouns of class 9 that do not have any reflex of this historical *n, as in (3). These

\footnotetext{
${ }^{3}$ The class 9 prefix is sometimes analyzed as /iN-/, with a homorganic nasal consonant (see, e.g., Taraldsen 2010). We take the nasal segment in question to be part of the following stem, and thus give the class prefix simply as [i-], rather than [iN-]. Note however, that even if words like [ink'omo] 'cow' are parsed as [in-k'omo], with the nasal in the prefix, the ambiguity of class 5 and 9 still does arise in words that (i) have a root-initial nasal, like [i-moto] 'car', and those that have no nasal like the examples in (3).
} 
include recent borrowings from English and Afrikaans (3a), as well as much older presumed borrowings from Khoe (3b-e), and also at least some words of discernibly proto-Bantu origin (3f) (Bennett 2014:122, Tshabe et al. 1989/2003/2006). As such, the presence or absence of a nasal is also not a fully reliable indicator of whether a noun is class 5 or class 9 .

(3) Historical nasal of classes $9 / 10$ is not always present
a. i-ti [íí] 'tea'
b. i-tyuwa [ícùwà] 'salt'
c. ilíhàgù] 'pig'
d. i-qhilika [í!'ílikà] 'trad. honey mead'
e. i-qhiya [í! ${ }^{1}$ jà $]$ 'traditional-style head scarf'
f. i-hambelo [íhámbèlò] 'a visit to a place or person for some purpose' (<-hamba 'go, walk')

When present, the nasal of class 9 (and its plural counterpart, class 10) induces certain changes to following consonants. These changes include de-aspiration of stops (which become ejectives); voicing of clicks; fortition of fricatives and $/ 1 /$; and neutralization of implosive [6] to voiced [b]. ${ }^{4}$ Such changes can be observed in limited form synchronically, through derivation of verb stems into class 9 or class 10 , and with the adjectival agreement marker of class 9 , which systematically retains its nasal, as in (4). These changes also occurred historically, and hold as static morpheme structure constraints. For example, Proto-Bantu *k has the reflex [ $\left.\mathrm{k}^{\prime}\right]$ after homorganic nasals, but $\left[\mathrm{k}^{\mathrm{h}}\right]$ elsewhere.

(4) Example post-nasal consonant changes in class 9

a. De-aspiration: -k'ûlù 'big' > énk'ûlù 'CL9.big'

b. Fortition: -lé 'pretty, fine' > éntlé 'CL9.pretty'

The changes induced by the nasal of class 9 did not occur with class 5 (which had no nasal historically). This asymmetry implies a phonotactic possibility to disambiguate classes 5 and 9 , on the basis of the initial consonant of the root. If a root begins with a consonant that looks like the result of post-nasal alternations (a "post-nasal output"), it is reasonable to infer that it has undergone such changes historically - and therefore presumably belongs to class 9 , which historically had a nasal. Conversely, if a root begins with a consonant that should undergo such post-nasal changes (a "post-nasal input"), it is reasonable to infer that it did not historically follow a nasal - and therefore that it must not be class 9 , and must rather be class 5 .

The pathway leading to this state of phonotactic disambiguation is illustrated in (5) below, with the root /-khûlù/ 'big', from proto-Bantu *-kúdù. This root has reflexes in both class 5 and in class 9: ([îk ${ }^{\mathrm{h}}$ ûlù] 'hundred' (cl.5) and [ínk'ûlù] 'eldest son of a family' (cl.9). These two words show a difference in the initial consonant: the form in class 5 has aspirated $\left[\mathrm{k}^{\mathrm{h}}\right]$, while the form in class 9 has undergone post-nasal de-aspiration, yielding [k']. The quality of the initial consonants thus serves a redundant indicator of their class membership: initial [k'] signals class 9 , while initial [ $\left.\mathrm{k}^{\mathrm{h}}\right]$ signals class 5 . As such, even if the nasal in the class 9 form were subsequently deleted, it should still be possible to distinguish between nouns of these two classes because of the phonotactic "footprint" left by post-nasal consonant changes. Consequently, even though the class marking prefixes are homophonous, speakers should be able to disambiguate based on whether the initial consonant (i) looks like one that has undergone post-nasal de-aspiration, or (ii) looks like one that would have undergone de-aspiration.

(5) Pathway leading to phonotactic disambiguation

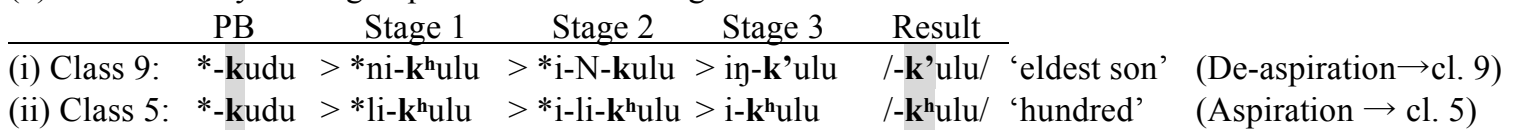

\footnotetext{
${ }^{4}$ For more on the phonetic characteristics of this alternation, see Halpert (2012), and Bennett (2014).
} 


\section{Hypothesis and predictions}

Given that the historical remnants of various phonological processes are detectable synchronically, we set out to examine whether speakers of Xhosa can make noun class judgments based on these phonotactic clues. In particular, speakers may be expected to use knowledge of the phonotactic patterns set up by the historical post-nasal sound changes as clues to noun class. Generalizing to the post-nasal alternations as a whole, we can state our hypothesis as follows.

(6) Hypothesis: phonotactic disambiguation of class 5 and class 9 nouns

a. If the root-initial consonant is a potential output of post-nasal consonant changes (a "post-N output"), then speakers can infer that it is class 9

b. If the root-initial consonant is a potential input of post-nasal consonant changes (a "post-N input"), then speakers can infer that it is not class 9 (and therefore must be class 5)

These hypotheses predict that when Xhosa speakers are uncertain of the class of a noun, such as when its morphology is ambiguous between class 5 and class 9, they will be biased towards one interpretation or the other based on the initial consonant of the root. To test this hypothesis, we conducted an experiment, described in the next section.

\section{Methods and materials}

4.1 Stimuli Two sets of 10 nonce nouns were created. The first set contains root-initial consonants of the post-N output category - including deaspirated stops - compatible with only a class 9 interpretation. The second set contains root-initial post- $\mathrm{N}$ inputs - including aspirated stops and non-fortited fricatives and liquids - which are compatible with a class 5 interpretation. The list of stimuli is provided in (2). All nonce nouns were preceded with the noun class prefix $i$-, which is ambiguous between class 5 and class 9. Among the 20 stimuli, half were of the form i-CV and half were of the form i-CVCV, evenly divided between the two sets. The stimuli items used are listed in (7), given both in Xhosa orthography and with expected pronunciation. (Tone is not marked in Xhosa orthography, so speakers were given no direct tonal information for the nonce forms; we therefore do not mark tone here.)

\begin{tabular}{|c|c|c|c|}
\hline \multicolumn{4}{|c|}{ Nonce items presented } \\
\hline Post-Nc & ss 9 interpretation) & Post-N il & ss 5 interpretation) \\
\hline$i-k i$ & [iki] & i-khelu & {$\left[\mathrm{ik}^{\mathrm{h}} \mathrm{elu}\right]$} \\
\hline$i$-tusa & [itusa] & i-thunka & [ithuyk'a] \\
\hline i-pula & [ipula] & $i$-phe & {$\left[i p^{h} e\right]$} \\
\hline$i$-gesha & [ige $\left.\int a\right]$ & $i-l u$ & [ilu] \\
\hline$i-d u$ & [idu] & $i-l u v a$ & [iluva] \\
\hline$i-b h i$ & [ibi] & i-lama & [ilama] \\
\hline$i-n u$ & [inu] & $i$-se & [ise] \\
\hline i-moke & [imoke] & i-hlonu & [iłonu] \\
\hline$i-n y u$ & [inu] & $i$-she & [ife] \\
\hline$i$-ngoya & [ingoja] & $i-b e$ & [ibe] \\
\hline
\end{tabular}

4.2 Experimental design In this experiment, native speakers of Xhosa were shown a singular nonce noun in Xhosa orthography and were asked to provide its plural form in a standard wug test paradigm (Berko 1958). All nonce nouns were given the noun class prefix $i$-, which is ambiguous between class 5 and class 9. Participants should provide the noun class 6 plural (ama-) if they interpret the nonce noun as class 5 , and the class 10 plural ( $i$ i-/izi-) if they interpret the nonce noun as class 9.

For example, if a participant sees the stimulus item $i$-phe, they might reply either ii-phe or izi-phe (both possible class 10 plural prefixes, indicating interpretation of as class 9) or ama-phe (class 6 plural, 
indicating interpretation as class 5).

The order of nouns was randomized per participant. Test items were interspersed with 20 filler items that were part of an unrelated experiment. Stimuli are segregated here into prefix and root for the reader, but the forms presented to participants were not (e.g. ihlonu, not i-hlonu). Speaker responses were recorded as audio, and coded for which prefix they supplied in the plural form.

4.3 Participants 10 native speakers of Xhosa participated in this experiment. Half of the participants were male, and half were female. Speakers ranged in age between 21-42 years old (mean 26 years old). All participants also spoke at least some English, and Afrikaans, Sotho, and Zulu were each spoken by 2 participants. At the time of the experiment, all of the participants were living in South Africa's Eastern Cape, in the area Grahamstown. Two speakers indicated that they had grown up partly in other places: one in Johannesberg, and one in Cape Town. All indicated that they spoke Xhosa as their primary home language.

\section{Results}

Our findings show that when a nonce item starts with a consonant that is the output of post-nasal sound changes, speakers are more likely to treat it as a class 9 noun.

Participants' responses were conditioned by which stimulus set an item belonged to $\left(\chi^{2}(1, N=194)=\right.$ $9.99, \mathrm{p}<0.005$ ). While $61.5 \%$ of the stimuli compatible with class 5 received an $a m a$ - (class 6 ) prefix, only $35.5 \%$ of the stimuli compatible with only class 9 did. Similarly, $37.5 \%$ of the stimuli compatible with class 5 received an ii-/izi- prefix, while $64.5 \%$ of the stimuli compatible only with class 9 did. $^{5}$ These results are shown in the figure in (8).

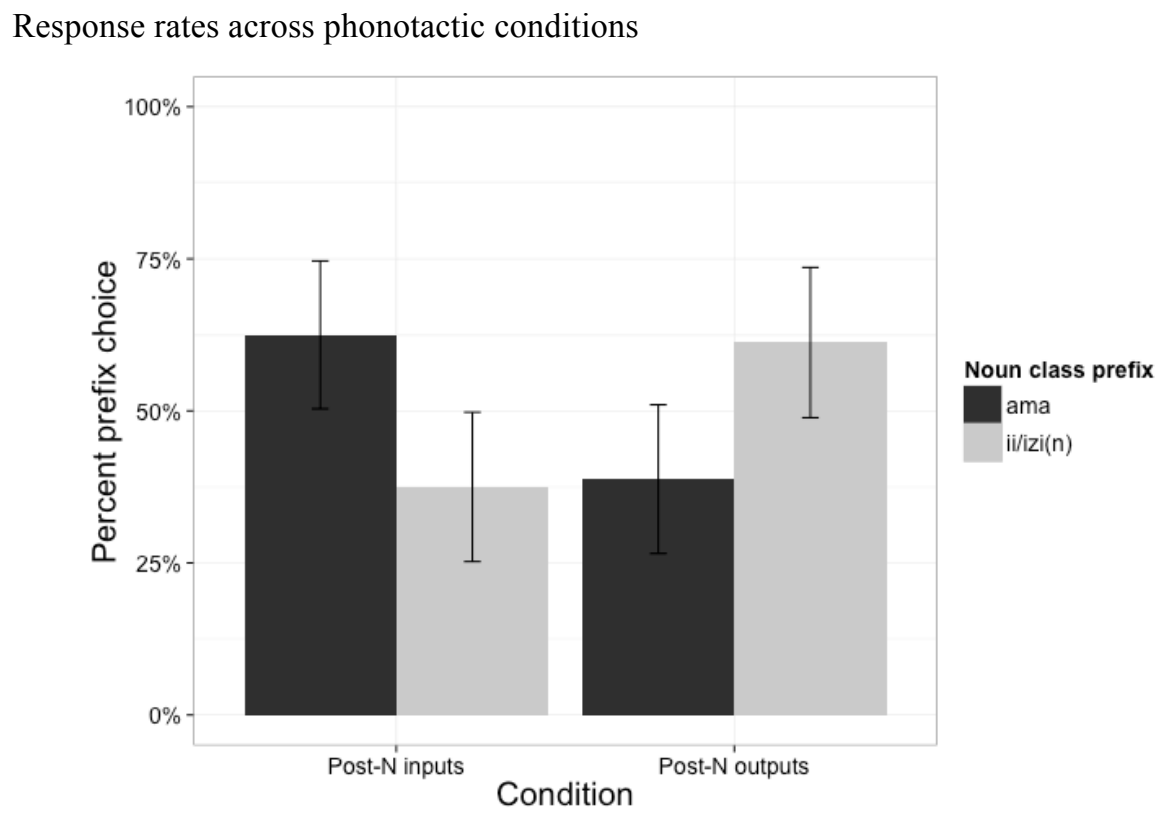

\section{Discussion}

The hypothesis we started from is that the results of post-nasal consonant changes can help clue speakers in to the historical presence of a nasal consonant - thereby providing a synchronically-visible clue that a noun belongs to class 9 , even though the dedicated class-marking morphology is ambiguous. Our

\footnotetext{
${ }^{5} 1 \%$ of responses in the post-N inputs condition supplied other prefixes, such as class $1 \mathrm{um}$-, and were excluded from the analysis.
} 
findings show that speakers are more likely to treat a nonce noun as class 9 if its initial consonant looks like the result of post-nasal consonant changes (i.e., it is a post-N output). By the same token, if the initial consonant is one that could have undergone historical post-nasal changes (i.e., a post-N input), speakers are more likely to treat it as class 5. We interpret this to mean that when speakers are deprived of syntactic and semantic cues to a noun's class, they can still use the phonotactic vestiges left by the historical post-nasal sound changes to choose an appropriate noun class.

We note also that this tendency is not absolute. This has consequences for the broader analysis of the phenomenon. For instance, it is not the case that features of the root-initial consonant serve as an overt marking of class morphology (à la consonant mutation phenomena in various other languages). Rather, speakers seem to attend to the phonotactic norms of each class. This result has a distinctly 'business as usual' feel to it: it is squarely in line with previous work showing that speakers can generalize probabilistic regularities in the lexicon to novel words (Ernestus \& Baayen 2003, Hayes et al. 2009, Moore-Cantwell 2016 , etc.), as well as previous work that finds that speakers readily extend gender systems to new forms (see Corbett 1991 for a review of some of the relevant literature). Whether our participants have internalized a phonotactic generalization from known nouns of class 5 and class 9 , and used it as the basis for categorizing nonce nouns, remains to be seen, pending further work quantifying these trends in the lexicon.

\section{Conclusions}

In this paper, we have shown that phonotactic tendencies can serve as redundant cues to noun class in Xhosa. We have demonstrated that when speakers are deprived of syntactic, semantic, and morphological bases to categorize nouns, they still have intuitions about which class a noun belongs in, based on its phonotactic profile.

We speculate that the effect we find here, in Xhosa, is merely the tip of the proverbial iceberg: there are probably numerous other phonotactic generalizations to be drawn about the nouns belonging to various noun classes, and this phenomenon probably generalizes far outside of Xhosa. We suspect that one of the reasons why Bantu languages have so robustly retained - and elaborated - their rich noun class systems is that they are underpinned not only by semantic structure, but also by phonotactic patterns. If so, this would link Bantu-style systems of grammatical gender to other languages with gender systems conditioned in part by the phonological form of nouns.

\section{References}

Bennett, Wm. G. 2014. Some differences between clicks and labio-velars. South African Journal of African Languages, 34(2):115-126.

Corbett, Greville G. 1991. Gender. Cambridge: Cambridge University Press.

Ernestus, Mirjam, and Harald Baayen. Predicting the unpredictable: Interpreting neutralized segments in Dutch. Language, 79(1):5-38, 2003.

Hayes, Bruce, Kie Zuraw, Péter Siptár, and Zsuzsa Londe. 2009. Natural and unnatural constraints in Hungarian vowel harmony. Language, 85(4):822-863.

Halpert, Claire. 2012. Overlap-driven consequences of nasal place assimilation. In Philip Hoole, Lasse Bombien, Marianne Pouplier, Christine Mooshammer, and Barbara Küuhnert, eds., Consonant clusters and structural complexity, 345-368. Mouton de Gruyter

Idiata, D. F. 2005. What Bantu child speech data tells us about the controversial semantics of Bantu Noun class system. Lincom.

Katamba, F. 2003. Bantu Nominal Morphology. In Derek Nurse \& Geraldine Philippson, eds., The Bantu Languages, 103-120. Routledge.

Moore-Cantwell, Claire. 2016. The phonological grammar is probabilistic: New evidence pitting abstract representation against analogy. Proceedings of the 2015 Annual Meeting in Phonology.

Moreton, E. and S. Amano. 1999. Phonotactics in the perception of Japanese vowel length: Evidence for long-distance dependencies. Proceedings of the 6th European Conference on Speech Communication and Technology.

Tucker, G.R., W.E. Lambert, and A.A. Rigault. 1977. The French Speaker's Skill with Grammatical Gender: An Example of Rule-Governed Behaviour. The Hague: Mouton. 
Taraldsen, Knut Tarald. 2010. The nanosyntax of Nguni noun class prefixes and concords. Lingua, 120(6): 1522-1548. Tshabe, S.L., et al. 2006. The Greater Dictionary of IsiXhosa. Volumes 1-3, previously published in 1989, 2003. IsiXhosa National Lexicography Unit. Alice, South Africa: University of Fort Hare. 